\section{Conclusions}

Model calculations based on $\gamma$-ray diffractometry of the diffraction properties of imperfect single crystals and systematic comparison of the results with those obtained by neutron diffraction experiments are helpful if one intends to improve the diffraction properties of the crystal. It is important to know whether a low neutron reflectivity is due to primary extinction or to inhomogeneities in the mosaic structure.

In order to solve the extinction problems in accurate structure factor measurements, perhaps more effort should be made in the development of experimental methods to allow for proper extinction correction; on the other hand one should develop techniques allowing a change in the effective degree of perfection of the given sample (e.g., fast neutron irradiation, deformation).

It is a great pleasure to thank Professor H. MaierLeibnitz for suggesting the investigations by means of $\gamma$-ray diffractometry and for his continued interest in this subject. I express my gratitude to Professor S. E.
Rasmussen for many very helpful discussions. Thanks are also due to $\mathrm{Dr} \mathrm{B}$. Dorner for supplying the large copper crystal, to $\mathrm{Mr}$ N. Thillosen for improving the electronics of the $\gamma$-diffractometer, and to Miss A. Hartmann for help with the $\gamma$-ray measurements.

\section{References}

BECKER, P. J. (1973). Private communication. BeCKer, P. J. \& Coppens, P. (1974). Acta Cryst. A 30, 129147, 148-153.

Darwin, C. G. (1914). Phil. Mag. 27, 315, 657.

Darwin, C. G. (1922). Phil. Mag. 43, 800.

DORNER, B. (1971). J. Appl. Cryst. 4, 185-190.

Freund, A. (1974). A Neutron Monochromator System consisting of Deformed Crystals with Anisotropic Mosaic Structure. To be published in Nucl. Instrum. Meth.

Maier-Leibnitz, H. (1967). Ann. Acad. Sci. Fenn. AVI, 267.

SCHNeIDER, J. R. (1974a). J. Appl. Cryst. 7, 541-548.

SCHNEIDER, J. R. (1974b). J. Appl. Cryst. 7, 547-554.

Thomas, P. (1972). J. Appl. Cryst. 5, 78-83, 83-88.

ZaChariasen, W. H. (1945). Theory of $X$-Ray Diffraction in Crystals. New York: John Wiley.

Zachariasen, W. H. (1967). Acta Cryst. 23, 558-564.

J. Appl. Cryst. (1975). 8, 201

\title{
A Precise X-ray Diffraction Study of Elastically Deformed Silicon Monocrystals
}

\author{
BY T. W. BAKER \\ Atomic Energy Research Establishment, Harwell, Didcot, Berkshire, England
}

(Received 29 April 1974)

\begin{abstract}
Silicon monocrystals $4 \times 20 \mathrm{~mm}$ and of thickness varying between 0.15 and $0.62 \mathrm{~mm}$, fixed at one end and bent by varying amounts by deflecting the other end, have been examined using radiations of differing penetrations $(\mathrm{Cr} K \beta, \mathrm{Cu} K \alpha, \mathrm{Cu} K \beta, \mathrm{Mo} K \alpha$ and $\operatorname{Ag} K \alpha)$. The measurements were carried out using the APEX Goniometer employing techniques described previously [Baker, T. W., George, J. D., Bellamy, B. A. \& Causer, R. (1968). Advanc. X-ray Anal. 11, 359-375; (1969). Fully Automated High Precision X-ray Diffraction, Report AERE-R 5152, Atomic Energy Research Establishment, Harwell, Berkshire]. Diffraction angles are measured with a precision which when translated into interplanar spacings gives these to better than one part in a million, and the changes in these with amount of bend, specimen thickness and penetration constitute the main part of the study; measurements of radii of curvature, intensity and breadth are also included. The techniques are briefly described and the experimental results are presented together with some discussion. The study originated from an investigation into the strain induced in silicon crystals when these were mounted on headers in the manufacture of electronic devices, but its development as presented is of more general interest.
\end{abstract}

